\title{
Priapismo secundario a infiltración peneana por contigüidad de carcinoma vesical infiltrante
}

\author{
Celma Doménech A, Planas Morin J, de Torres Ramírez I*, Bestard Vallejo J, Mir Marisma C, \\ Morote Robles J.
}

Servicio de Urología. *Servicio de Anatomía Patológica. Hospital Vall d’Hebrón. Barcelona.

Actas Urol Esp. 2008; 32(7):749-751

\section{RESUMEN}

PRIAPISMO SECUNDARIO A INFILTRACIÓN PENEANA POR CONTIGÜIDAD DE CARCINOMA VESICAL INFILTRANTE

El priapismo de origen metastático es una entidad muy poco frecuente que se produce por implantación de células tumorales, o bien, por invasión directa por contigüidad de los cuerpos cavernosos. Hasta en un 80\% de los casos el origen de los tumores primarios es genitourinario, principalmente por tumores prostáticos y vesicales. El tratamiento dependerá de la sintomatología que produzca y del pronóstico del paciente; pero generalmente, la supervivencia al año es muy pobre debido a que presentan una neoplasia en fase metastásica.

Presentamos un caso de priapismo por invasión por contigüidad de los cuerpos cavernosos secundario a un carcinoma vesical.

Palabras clave: Priapismo. Metástasis. Carcinoma vesical.

\section{ABSTRACT}

PRIAPISM SECONDARY TO PENIS INFILTRATION OF BLADDER CANCER

Metastasic priapism is a rare entity produced by tumor cell implantation or direct infiltration of corpora cavernousum of the penis. In up to $80 \%$ of cases the primary tumor has an urological origen like prostate or bladder cancers. Treatment depends on syntomatology and patient's prognosis. Generally, average survival in these patients is poor due to metastasic progression, among 1 to 1 and a half years.

We present a case report of secondary priapism for direct invasion of the corpora cavernousum of the penis for bladder carcinoma.

Keywords: Priapism. Metastasis. Bladder carcinoma.

$\mathrm{E}$ priapismo se define como una erección prolongada que dura más de 6 horas en ausencia de estímulo sexual ${ }^{1}$. Etiológicamente se puede distinguir entre priapismo idiopático y secundario. Las principales causas de priapismo secundario son el uso o abuso de sustancias tóxicas o farmacológicas $^{2}$, las alteraciones hematológicas, la afectación metastásica del pene por tumores de otro origen, la tromboflebitis pélvica, determinadas alteraciones neurológicas y trastornos metabólicos.

El priapismo de origen metastático es muy infrecuente, 3-8\% de los priapismos ${ }^{3}$. En estos casos, la erección se debe a una obstrucción del flujo venoso peneano, o bien, a la infiltración de los cuerpos cavernosos por células tumorales. Los tumores primarios que con mayor frecuencia pueden producir este proceso son prostáticos y vesicales, seguidos de los renales y de rectosigma. Otras localizaciones menos frecuentes son testículo, páncreas, hígado, estómago, pulmón, nasofaringe y melanomas ${ }^{4}$.
En este artículo, presentamos un caso de un paciente con historia de tumores uroteliales que presenta un cuadro de priapismo de larga evolución por infiltración metastática, que actúa como foco séptico por el desarrollo de una necrosis infectada a nivel del glande.

\section{CASO CLÍNICO}

Paciente de 62 años de edad sin alergias medicamentosas conocidas, con antecedentes de síndrome depresivo en tratamiento médico, diagnosticado de tumor vesical infiltrante (pT2G2) hace 11 años por el que realizó tratamiento conservador con Resección trasuretral (RTU) + quimioterapia con Cisplatino y Radioterapia (RT) adyuvantes. El paciente permaneció libre de enfermedad durante 11 años. Tumor ureteral distal izquierdo diagnosticado por urografía endovenosa hace 6 meses sometiéndose a Nefroureterectomía izquierda (Anatomía patológica: Carcinoma urotelial 
pT3G3). RTU por recidiva de tumor vesical (pT2G3) hace 3 meses con afectación de trígono, por lo que se inició tratamiento quimioterápico con Carboplatino y Gemcitabina de forma adyuvante, descartándose cirugía radical.

El paciente ingresa procedente de urgencias, donde acude por mal estado general, disminución del nivel de consciencia y fiebre. A su llegada a urgencias el paciente presentaba fiebre de $39^{\circ} \mathrm{C}$ con un cuadro de escalofríos francos y obnubilación. El abdomen era blando y depresible, no peritonítico. Se objetivó pene tumescente con glande necrótico y con supuración purulenta y con adenopatías inguinales bilaterales palpables. TR con próstata mediana de consistencia pétrea. Se solicita valoración por el servicio de neurología que objetiva un cuadro confusional con desorientación y afasia, sin déficit campimétrico ni déficits motores aparentes. La analítica sanguínea mostraba: Hematocrito 36,1\%, 10.000 leucocitos, 87\% neutrófilos, 175.000 plaquetas, coagulación y función renal normal. Se le practica una TC cerebral que descartó la presencia de lesiones agudas y una ecografía abdominal que no objetivó alteraciones. El despistaje de BZD, barbitúricos y opiáceos en sangre que resultó negativo.

Se orientó el caso como un cuadro séptico de origen genitourinario secundario a necrosis purulenta de glande por lo que se practicó una penectomía total + uretrostomía perineal.

Durante el postoperatorio se le realizó una TC abdómino-pélvica que informó de la presencia de 3 imágenes hepáticas hipodensas puntiformes inespecíficas. Masas suprarrenales bilaterales hipodensas no sugestivas de adenomas, adenopatías mayores de $1 \mathrm{~cm}$ periaortocavas, masa delante de psoas iliaco izquierdo de $3 \mathrm{~cm}$ compatible con recidiva local. Vejiga urinaria con paredes difusamente engrosadas de predominio en cara anterior y con infiltración de grasa perivesical. Los hemocultivos y urocultivos realizados resultaron negativos (probablemente debido a que el paciente había estado tomando AmoxicilinaClavulánico durante la semana previa). Interrogando al paciente explicaba que presentaba un priapismo no doloroso desde hacía un mes y que hacía una semana había presentado una macha necrótica en el glande, por lo que había iniciado el tratamiento antibiótico (siguiendo prescripción de médico de familia). El paciente presentó una buena evolución clínica, por lo que fue dado de alta.
La anatomía patológica mostró una invasión de todo el pene con infiltración de los cuerpos cavernosos y del tejido fibroso circundante por carcinoma urotelial de alto grado (Figs. 1, 2 y 3).

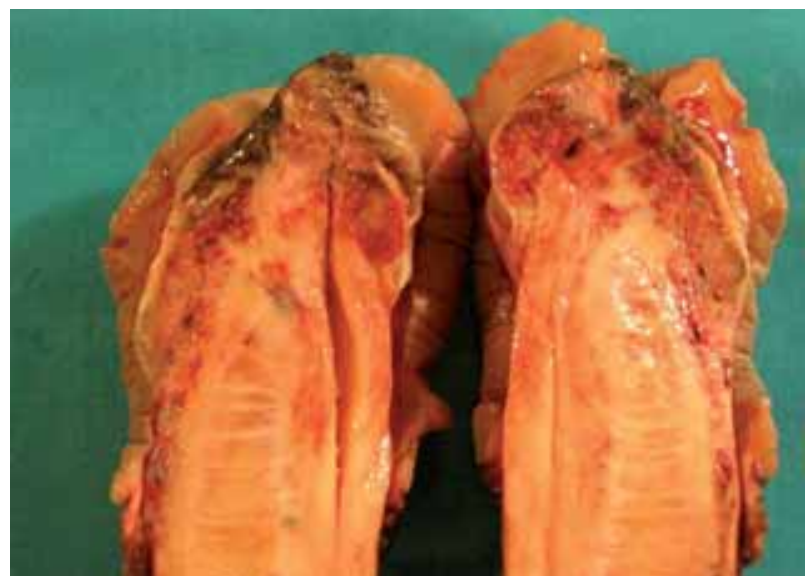

FIGURA 1. Imagen macroscópica de pieza de penectomía en la que se aprecian los cuerpos cavernosos con infiltración tumoral.

El paciente fue dado de alta orinando clara y espontáneamente a través de la uretrostomía perineal. Actualmente prosigue con el tratamiento quimioterápico que había iniciado (CBP-GEM), presentando en estos momentos una estabilización de su patología.

\section{DISCUSIÓN}

Existen diferentes estudios que demuestran que en casos seleccionados, el tratamiento conservador del tumor vesical infiltrante con RTU + quimioterapia + radioterapia presenta similares tasas de supervivencia que la cistectomía radical, con efectos adversos tolerables y conservando la vejiga ${ }^{5,6}$. De hecho este paciente en un origen fue sometido a tratamiento conservador de su tumor vesical infiltrante, manteniéndose libre de enfermedad durante 11 años. Sin embargo, la evolución de su tumor urotelial en los últimos 6 meses ha sido muy rápida, por lo que en este caso se inició el tratamiento quimioterápico adyuvante con intención paliativa.

El priapismo asociado a tumores sólidos suele producirse por metástasis o por infiltración directa de los cuerpos cavernosos, seguida del glande y del cuerpo esponjoso ${ }^{7}$. En el $80 \%$ de estos casos, los tumores primarios son de origen genitourinario ${ }^{8}$. En nuestro caso se trata de un tumor vesical que presenta una progresión local con infiltración por contigüidad de los cuerpos cavernosos. 

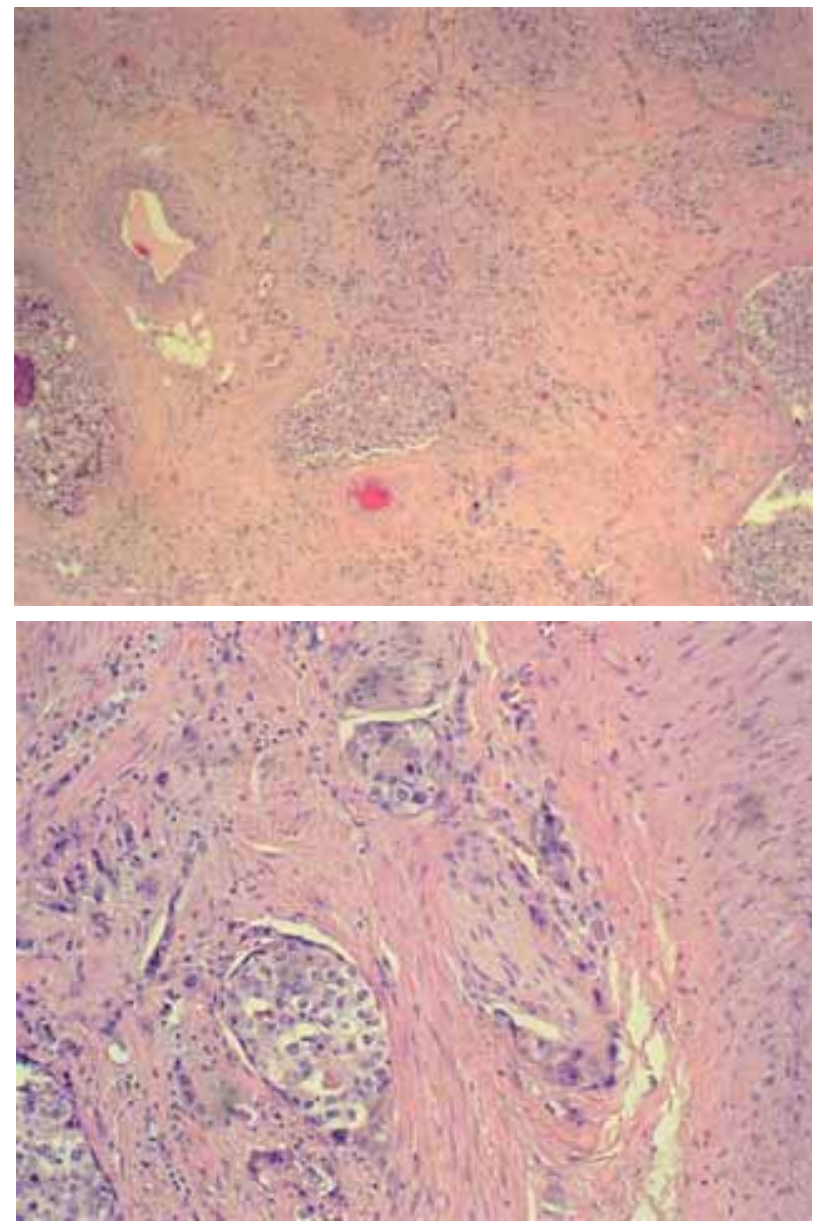

FIGURAS. 2 y 3. Imagen microscópica en la que se aprecia la invasión de los cuerpos cavernosos por nidos de carcinoma urotelial de alto grado con focos de necrosis intratumoral.

Dada la evolución que estaba teniendo su tumor urotelial y el estado en el que llegó el paciente, las principales posibilidades que se plantearon como causa del priapismo fue la infiltración metastásica o una reacción leucemoide, que es un síndrome en este caso paraneoplásico, en el que se produce una obstrucción mecánica intravascular secundaria a una hiperviscosidad sanguínea, y donde la analítica sanguínea simula una leucemia mieloide crónica con una leucocitosis intensa ${ }^{3}$, que en este caso quedó descartado.

El tratamiento del priapismo de origen neoplásico es controvertido. El priapismo en estos casos no suele responder a las medidas conservadoras (inyección de drogas vasoactivas), o a la realización de shunts que utilizamos en los priapismos secundarios a otras causas. La decisión de tratar o no el priapismo de origen neoplásico y la modalidad de tratamiento dependerá en su mayor parte del estado clínico y del pronóstico del enfermo. Las lesiones metastásicas en pene se pueden tratar quirúrgicamente con escisión de la lesión, penectomía parcial o total, quimioterapia, radioterapia o con tratamiento conservador ${ }^{2}$.

Presentamos un caso infrecuente de necrosis balánica sobreinfectada secundaria a un priapismo de origen neoplásico muy evolucionado. En este caso, habiéndose descartado otros focos responsables del estado del paciente se procedió a practicarle una penectomía con buena evolución posterior. Aunque el paciente ha reiniciado el tratamiento con quimioterapia con estabilización de su enfermedad, el priapismo por infiltración neoplásica es un signo de mal pronóstico con supervivencias muy bajas al año de su aparición ${ }^{4}$.

\section{REFERENCIAS}

1. Keoghane SR, Sullivan ME, Millar MA. The aetiology, pathogenesis and management of priapism. BJU Int. 2002;90(2): 149-154.

2. Guvel S, Kilinc F, Torun D, Egilmez T, Ozkardes H. Malignant priapism secondary to bladder cancer. J Androl. 2003;24(4):499500.

3. Rodríguez A, Romero E, Suárez G, Bonelli C, González A, Lorenzo $J$, et al. Priapismo secundario a reacción leucemoide paraneoplásica en paciente con cáncer de vejiga. Actas Urol Esp. 2004;28(7): 539-543.

4. Trivez Boned MA, Aranda Lassa JM, Lozano Enguita J, Ambroj Navarro C, Cebrián C. Carcinoma transicional y priapismo metastático. Actas Urol Esp. 2004;28(9):694-697.

5. Michaelson MD, Shipley WU, Heney NM, Zietman AL, Kaufman DS. Selective bladder preservation for muscle-invasive transitional cell carcinoma of the urinary bladder. Br J Cancer. 2004; (90):578-581.

6. Kuczyk M, Turkeri L, Hammerer P, Ravery V; European Society for Oncological Urology. Is There a role for Bladder Preserving Strategies in the Treatment of Muscle-Invasive Bladder Cancer?. Eur Urol. 2003;44(1):57-64.

7. Robey EL, Schellhammer PF. Tour cases of metastases to the penis and a review of the literature. J Urol. 1984;132(5):992-994.

8. Chan PTK, Begin LR, Arnold D, Jacobson SA, Corcos J, Brock GB. Priapism secondary to penile metastasis: a report of two cases and a review of the literature. J Surg Oncol. 1998;68(1):51-59.

Correspondencia autor: Dra. A. Celma Doménech Servicio de Urología

Hospital Univ. Vall D’Hebrón

Passeig de la Vall D’Hebrón 119-129 - 08035 Barcelona

Tel.: 932746000

E-mail autor: anacelmad@hotmail.com

Información artículo: Nota Clínica

Trabajo recibido: enero 2007

Trabajo aceptado febrero 2007 